\title{
FAKTOR YANG MEMPENGARUHI HASIL BELAJAR SISWA MENGGUNAKAN ANALISIS DISKRIMINAN MI NURUL IMAN KOTA TANGERANG SELATAN
}

\author{
Sulaeman $^{1 *}$ \\ ${ }^{1}$ Universitas Pamulang \\ E-mail: lemans276@gmail.com ${ }^{1 *}$
}

\begin{abstract}
This study aims to determine what factors influence learning achievement. This study aimed to create a discriminant model of learning achievement from the influencing factors. The object of this research is the students of MI Nurul Iman, South Tangerang City. The variables used are six variables. The dependent variable in this study is the average report card, while the independent variables are motivation (X1), Learning Methods (X2), Teacher Competence (X3), Parental Environment (X3), School Infrastructure (X5), Community Environment (X6), which used as many as 56 samples. Based on the results of the output of the discriminant model using the SPSS version 21 program, it shows that the factors that affect student learning outcomes are School Facilities (X5). The discriminant model formed to determine the discriminant function is from the factors that affect learning achievement. Apart from 1, these variables are not used. Then the following function is obtained: $\mathrm{D}=-3,980+0,369 X_{5}$
\end{abstract}

Keywords: Learning Factors, Learning Outcomes, Discriminant Analysis,

\begin{abstract}
Abstrak
Penelitian ini bertujuan untuk mengetahui faktor-faktor apa saja yang mempengaruh prestasi belajar. Tujuan penelitian ini adalah membuat model diskriminan prestasi belajar dari faktor-faktor yang berpengaruhi. Objek penelitian yang digunakan adalah siswa MI Nurul Iman Kota Tangerang Selatan. Variabel yang digunakan terdapat enam variabel. Variabel dependen dalam penelitian ini adalah Rata rata Raport, sedangkan variabel independen adalah motivasi $\left(\mathrm{X}_{1}\right)$, Cara Belajar $\left(\mathrm{X}_{2}\right)$, Kompetensi Guru $\left(\mathrm{X}_{3}\right)$, Lingkungan Orang Tua $\left(\mathrm{X}_{3}\right)$, Sarana Prasarana Sekolah $\left(\mathrm{X}_{5}\right)$, Lingkungan Masyarakat $\left(\mathrm{X}_{6}\right)$, yang digunakan sebanyak 56 sampel. Berdasarkan hasil output model diskriminan menggunakan Progam SPSS versi 21 menunjukan bahwa faktor-faktor yang mempengaruhi hasil belajar siswa yaitu Sarana Prasarana Sekolah $\left(\mathrm{X}_{5}\right)$. Model diskriminan yang dibentuk untuk menentukan fungsi diskriminan adalah dari faktor-faktor yang mempengaruhi prestasi belajar. Selain 1 variabel tersebut tidak digunakan. Maka diperoleh fungsi sebagai berikut: $\mathrm{D}=-3,980+0,369 X_{5}$
\end{abstract}

Kata Kunci : Faktor-faktor Belajar, Hasil Belajar, Analisis Diskriminan,

Received: September 09, 2021 / Accepted: December 01, 2021 / Published Online: December 30, 2021 
Jurnal Lebesgue : Jurnal Ilmiah Pendidikan Matematika, Matematika dan Statistika

Sulaeman

Volume 2, No. 3, Desember 2021 hal.256-266

DOI Artikel : $10.46306 /$ lb.v2i3.84

\section{PENDAHULUAN}

Pendidikan adalah interaksi informasi manusia yang diterapkan pada kegiatan pengajaran melalui hubungan personal peran individu di dalamnya. Perkembangan ilmu pengetahuan dan teknologi proses kegiatan belajar mengajar tersebut karna murid memiliki cara memahami dan mengerti suatu pembelajaran di kelas belum sama dengan pemahaman murid dengan bidang yang lain nya.

Maka dengan menentukan faktor yang berpengaruh pada diri siswa suatu sekolah harus didukung dengan data yang memadai untuk dapat menjadi acuan sehingga strategi yang dijalankan dapat optimal. Data tentang siswa perlu dianalisis agar data tersebut dapat dijadikan sebagai bahan informasi yang akurat. Sehingga analisis yang di gunakan untuk membedakan suatu faktor-faktor tersebut digunakan analisis diskriminan. Berdasarkan dari penjelasan sebelumnya maka penelitian ini bertujuan untuk mendapatkan faktor yang mempengaruhi proses pembelajaran siswa dari analasis dengan menggunakan analisis diskriminan Peneliti ingin mengetahui apakah fungsi diskriminan dapat membantu mengetahui faktor-faktor yang mempengaruhi hasil belajar siswa dan Untuk mendapatkan proses hasil pembelajaran siswa dengan menggunakan analisis diskriminan dari jawaban responden.

\section{METODE PENELITIAN}

\section{Metode Penelitian}

Pelaksanaan penelitian ini menggunakan metode penelitian deskriptif telah membatasi waktu sampai pengumpulan informasi dan pengaturan informasi, selain itu semua yang dikumpulkan dari penelitian ini untuk menjadi cara apa yang sedang diselidiki. Dari hasil pemeriksaan diskriminan dengan menggunakan perangkat SPSS, maka pada saat itu informasi disiapkan karena penyebaran kuesioner pendapat kepada responden.

\section{Tempat dan Waktu Penelitian}

Lokasi yang pilih sebagai tempat penelitian penulis faktor yang mempengaruhi prestasi belajar adalah MI Nurul Iman Kota Tangerang Selatan, Kecamatan Pondok Aren. Penelitian ini dilakukan selama bulan April 2021 sampai bulan Juni 2021. Penelitian ini di ambil secara bertahap dengan pra survei dari pendahuluan dan pengolahan data. 


\section{Populasi dan Sampel}

Populasi dalam penelitian ini targetnya ialah semua siswa MI Nurul Iman Kota Tangerang Selatan, sedangkan populasi terjangkaunya adalah jumlah anak-anak kelas IV ( emapat ),Va ( lima A ), Vb ( lima B ) dan VI ( enam ) adalah 125 siswa.

Berdasarkan populasi penelitian yaitu sebanyak 56 responden sampel diolah secara proporsional teknik sampling yang terbagi menjadi 2 (dua) sampel, yaitu sampel observasi sebanyak 69 respondoen dan sempel penelitian yaitu sebanyak 56 responden.

Untuk menentukan sampel yang akan dilakukan menggunakan rumus slovin:

$$
\mathrm{n}=\frac{N}{1+N \cdot e^{2}}
$$

Keterangan :

$\mathrm{N}=$ Total Populasi

$\mathrm{n}=$ Total Sampel

$e=$ estandar error $=10 \%(0.1)$

Maka :

$$
\begin{aligned}
n & =\frac{125}{1+125 \cdot(0,1)^{2}} \\
& =55,56=56
\end{aligned}
$$

\section{Tekhnik Pengumpulan Data}

Prosedur penelitian ini di lakukan dengan teknik pengumpulan data yang di lakukan dengan metode dokumentasi dan metode kuesioner.

\section{a. Metode Dokumentasi}

Bahan dokumentasi agar mendapatkan bahan yang di perlukan bahan yang di perlukan dalam peneltian yang akan di lakukan penulis ini yang berhubungan dnegan penelitian penulis dalam melaksanakan penelitian.

\section{b. Metode Kuesioner}

Dalam penelitian ini metode yang digunakan untuk memperoleh informasi dari responden adalah berbentuk angket atau kuesioner.

\section{Prosedur Penelitian}

Prosedur penelitian ini di laksanakan seperti berikut :

\section{a. Uji Validitas}

Adapun penghitungan secara manual dapat menggunakan metode pearson atau product 
Jurnal Lebesgue : Jurnal Ilmiah Pendidikan Matematika, Matematika dan Statistika

Sulaeman

Volume 2, No. 3, Desember 2021 hal.256-266

DOI Artikel : 10.46306/lb.v2i3.84

moment. Maka akan diperoleh nilai $\mathrm{Rh}$ (hitung) jika $\mathrm{R}_{\text {hitung }}>\mathrm{R}_{\text {tabel }}$ maka item-item tersebut akan validitas.

\section{b. Uji Reliabilitas}

Teknik yang digunakan adalah teknik nilai angka Cronbach's Alpha yang dengan bantuan softwere SPSS versi 17. Dan angka alpha cronbach yang ditafsirkan sesuai pembanding pada umumnya yaitu reliabilitas > 0.6 dapat dikatakan intrusmen yang dikatakan handal (reliabel).

\section{c. Uji Signifikansi Diskriminan}

Nilai signifikansi destiminasi ialah chi square yang telah di ubah dengan cara statistik . Jika nilai chi square hasil transformasi diatas $\alpha(0.05 \%)$, maka terima $\mathrm{H}_{0}$. Tapi jika nilai chi square hasil transformasi dibawah $\alpha(0.05 \%)$ maka tolak $\mathrm{H}_{0}$.

\section{d. Uji Validitas Diskriminan}

Nilai yang di dapat dari proses perhitungan dibandingkan dengan tingkat kritis kemudian nilai tersebut didapat dari tabel chi square dengan nilai satu (1) (ditulis $\mathrm{df}=1$ atau $\mathrm{dk}=1$ ) dengan tingkat keyakinan sesuai dengan penulispenelitian.

\section{e. Uji Hipotesis}

Intepretasi hasil analisis diskriminan tidak berguna jika fungsinya tidak signifikan. Hipotesis yang diuji adalah $\mathrm{H} 0$ yang menyatakan bahwa rata-rata semua variabel dalam semua kelompok adalah sama. Dalam SPSS 21, uji dilakukan dengan menggunakan wilks'lambda. Jika dilakukan pengujian sekaligus beberapa fungsi sebagaimana dilakukan pada analisis diskriminan.

Jika $F_{\text {hitung }} \geq F_{\text {tabel }}$ maka $H_{0}$ ditolak dan $H_{1}$ diterima

Jika $F_{\text {hitung }}<F_{\text {tabel }}$ maka $H_{0}$ diterima dan $H_{l}$ ditolak

\section{HASIL DAN PEMBAHASAN}

\section{Hasil}

\section{Menghitung Uji Validitas}

Dalam perhitungan uji validitas ini untuk mempermudah penulis menggunakan sofware SPSS 21. Dari tabel 1 menjelaskan bahwa butir pertnyaan dari X1 sampai dengan X6 dapat di katakan validitas karena nilai $r_{\text {hitung }}>0,237\left(r_{\text {tabel }}\right)$. Diketahui nilai $r_{\text {tabel }}$ pada tabel $r$ dengan $\mathrm{df}=\mathrm{n}-2(\mathrm{n}=$ jumlah sample) dengan tarafsignifikan $5 \%$.

Tabel 1. Validitas Instrumen 


\begin{tabular}{|c|c|c|c|c|}
\hline \multicolumn{2}{|c|}{ Pernyataan } & $\mathrm{R}_{\text {hitung }}$ & $\mathrm{R}_{\text {tabel }}$ & Validitas \\
\hline \multirow{5}{*}{$\mathbf{X} 1$} & Pertanyaan 1 & 0,91 & 0,263 & Validitas \\
\hline & Pertanyaan 2 & 0,803 & 0,263 & Validitas \\
\hline & Pertanyaan 3 & 0,848 & 0,263 & Validtas \\
\hline & Pertanyaan 4 & 0,795 & 0,263 & Validtas \\
\hline & Pertanyaan 5 & 0,875 & 0,263 & Validtas \\
\hline \multirow{5}{*}{$\mathrm{X} 2$} & Pertanyaan 1 & 0,862 & 0,263 & Validtas \\
\hline & Pertanyaan 2 & 0,838 & 0,263 & Validtas \\
\hline & Pertanyaan 3 & 0,85 & 0,263 & Validtas \\
\hline & Pertanyaan 4 & 0,587 & 0,263 & Validtas \\
\hline & Pertanyaan 5 & 0,409 & 0,263 & Validtas \\
\hline \multirow{5}{*}{$\mathbf{X} 3$} & Pertanyaan 1 & 0,803 & 0,263 & Validtas \\
\hline & Pertanyaan 2 & 0,83 & 0,263 & Validtas \\
\hline & Pertanyaan 3 & 0,756 & 0,263 & Validtas \\
\hline & Pertanyaan 4 & 0,762 & 0,263 & Validtas \\
\hline & Pertanyaan 5 & 0,562 & 0,263 & Validtas \\
\hline \multirow{5}{*}{ X4 } & Pertanyaan 1 & 0,614 & 0,263 & Validtas \\
\hline & Pertanyaan 2 & 0,698 & 0,263 & Validtas \\
\hline & Pertanyaan 3 & 0,832 & 0,263 & Validtas \\
\hline & Pertanyaan 4 & 0,707 & 0,263 & Validtas \\
\hline & Pertanyaan 5 & 0,677 & 0,263 & Validtas \\
\hline \multirow{5}{*}{ X5 } & Pertanyaan 1 & 0,826 & 0,263 & Validtas \\
\hline & Pertanyaan 2 & 0,875 & 0,263 & Validtas \\
\hline & Pertanyaan 3 & 0,717 & 0,263 & Validtas \\
\hline & Pertanyaan 4 & 0,774 & 0,263 & Validtas \\
\hline & Pertanyaan 5 & 0,757 & 0,263 & Validtas \\
\hline \multirow{5}{*}{ X6 } & Pertanyaan 1 & 0,63 & 0,263 & Validtas \\
\hline & Pertanyaan 2 & 0,633 & 0,263 & Validtas \\
\hline & Pertanyaan 3 & 0,612 & 0,263 & Validtas \\
\hline & Pertanyaan 4 & 0,605 & 0,263 & Validtas \\
\hline & Pertanyaan 5 & 0,719 & 0,263 & Validtas \\
\hline
\end{tabular}


Jurnal Lebesgue : Jurnal Ilmiah Pendidikan Matematika, Matematika dan Statistika

Sulaeman

Volume 2, No. 3, Desember 2021 hal.256-266

DOI Artikel : $10.46306 / 1 b . v 2 i 3.84$

\section{Menghitung Reliabilitas}

Diketahui tabel 2 nilai varian butir untuk pertanyaan no. 1 yang ditentukan kepada sample sebesar 1.170. kemudian melakukan perhitungan keseluruhan instrumen variabel X.

Tabel 2. Nilai Varian setiap butir pertanyaan

\begin{tabular}{|c|c|c|}
\hline VARIABEL & \multicolumn{2}{|c|}{$\begin{array}{l}\text { PERNYATAAN } \\
\text { NILAI VARIAN }\end{array}$} \\
\hline \multirow{5}{*}{$\mathrm{X} 1$} & 1 & 1,1706 \\
\hline & 2 & 0,6071 \\
\hline & 3 & 0,852 \\
\hline & 4 & 0,5277 \\
\hline & 5 & 1,3724 \\
\hline \multirow{5}{*}{$\mathrm{X} 2$} & 1 & 0,6936 \\
\hline & 2 & 0,9528 \\
\hline & 3 & 0,6757 \\
\hline & 4 & 0,3925 \\
\hline & 5 & 0,5599 \\
\hline \multirow{5}{*}{$\mathrm{X} 3$} & 1 & 1,0558 \\
\hline & 2 & 0,713 \\
\hline & 3 & 0,463 \\
\hline & 4 & 0,7589 \\
\hline & 5 & 0,4681 \\
\hline \multirow{5}{*}{$\mathrm{X} 4$} & 1 & 1,0153 \\
\hline & 2 & 0,6378 \\
\hline & 3 & 0,9439 \\
\hline & 4 & 0,6161 \\
\hline & 5 & 0,9592 \\
\hline \multirow{5}{*}{$\mathrm{X} 5$} & 1 & 1,2854 \\
\hline & 2 & 0,9614 \\
\hline & 3 & 0,3469 \\
\hline & 4 & 0,602 \\
\hline & 5 & 0,3112 \\
\hline X6 & 1 & 0,4439 \\
\hline
\end{tabular}




\begin{tabular}{l|l|l}
2 & 0,6247 \\
3 & 1,1467 \\
4 & 1,1327 \\
5 & 0,9439 \\
\hline
\end{tabular}

Selanjutnya menjumlahkan varians semua item instrument dengan rumus:

$$
\begin{aligned}
& \sum S_{i}=S_{1}+S_{2}+S_{3}+S_{4}+S_{5} \\
& \sum S_{i}=1,170+0,607+0,852+0,527+1,372 \\
& \sum S_{i}=4,530
\end{aligned}
$$

a) Mencari Reliabelitas

$$
\begin{aligned}
\mathrm{K}= & 5 \\
\Sigma \mathrm{si}^{2}= & 4,53 \\
\mathrm{~S} & =15,96 \\
\mathrm{t}^{2}= & \left(\frac{k}{k-1}\right)\left(1-\frac{\Sigma S_{i}}{S_{t}}\right) \\
r= & \left(\frac{5}{5-1}\right)\left(1-\frac{4,53}{15,96}\right) \\
r= & \left(\frac{5}{10-1}\right)(1-0,28) \\
r= & (1,25) \cdot(0,72) \\
r= & 0,90
\end{aligned}
$$

Hasil diatas dapat dikatakan reliable dikarenakan angka Cronbach Alpha $(\alpha)$ 0,90>0,60.

\section{Menghitung Analisis data dengan Analisi Diskriminan}

Nilai Wilks'Lambda bernilai 0,663 sampai0,888 . dari kolom tabel 3 dapat dinyatakan siginifikansi jika siginifikan > 0,05, tidak adanya pebedaan anatara kelompok. 
Tabel 3. Tests Of Equality Of Group

\begin{tabular}{cccccc}
\hline & $\begin{array}{c}\text { Wilks' } \\
\text { Lambda }\end{array}$ & $\mathrm{F}$ & $\mathrm{df1}$ & $\mathrm{df2}$ & Sig. \\
\hline $\mathrm{X} 1$ & 0,774 & 7,721 & 2 & 53 & 0,001 \\
\hline $\mathrm{X} 2$ & 0,855 & 4,491 & 2 & 53 & 0,016 \\
\hline $\mathrm{X} 3$ & 0,798 & 6,726 & 2 & 53 & 0,002 \\
\hline $\mathrm{X} 4$ & 0,799 & 6,665 & 2 & 53 & 0,003 \\
\hline $\mathrm{X} 5$ & 0,663 & 13,5 & 2 & 53 & 0,0006 \\
\hline $\mathrm{X} 6$ & 0,888 & 3,347 & 2 & 53 & 0,21 \\
\hline
\end{tabular}

\section{Menghitung Signifikansi}

Pada Tabel 4 Wilk's Lambda di atas menyatakan angka akhir dariWilks'Lambda, yang sebenarnya sama saja dengan angka terakhir dari step pembuatan model diskriminan. Angka Chi-Square sebesar 21,822 dengan tingkat signifikansi 0,001 jauh di bawah 0,05 menjelaskan perbedaan yang signifikan antara ketiga kelompok

Tabel 4. Wilk's Lambda

\begin{tabular}{ccccc}
\hline Test of Function(s) & $\begin{array}{c}\text { Wilks' } \\
\text { Lambda }\end{array}$ & Chi-square & Df & Sig. \\
\hline 1 & 0,663 & 21,822 & 2 & 0,001 \\
\hline
\end{tabular}

Structure Matrix menjelaskan korelasi antara variabel bebas dengan fungsi diskriminan.Bahwa variabel $X_{5}$ palingerathubungannya denganfungsi diskriminan, diikuti oleh variabel $X_{3}, X_{2}, X_{1}, X_{6}, X_{4}$. Dapat terlihat di tabel 5 .

Hanya di sini variabel $X_{3}, X_{2}, X_{1}, X_{6}, X_{4}$ tidak dimasukkan pada model diskriminan, dari tandahuruf a didekat variabel-variabeltersebut. 
Tabel 5. Structure Matrix

\begin{tabular}{|c|c|}
\hline & Function \\
\cline { 2 - 3 } & 1 \\
\hline$X 5$ & 1 \\
$X 3^{\mathrm{a}}$ & 0,624 \\
$\mathrm{X} 1^{\mathrm{a}}$ & 0,563 \\
$\mathrm{X} 6^{\mathrm{a}}$ & 0,547 \\
$\mathrm{X} 2^{\mathrm{a}}$ & 0,542 \\
$\mathrm{X} 4^{\mathrm{a}}$ & 0,514 \\
\hline
\end{tabular}

\section{Menghitung Koefesien}

Koefisien fungsi diskriminan kanonikmerupakan hasil akhir dari model analisis diskriminan. Tabel 6 memiliki fungsi yang hampir sama dengan persamaan regresi berganda, yang dalam analisis diskriminan disebutfungsidiskriminan.Dengan menggunakan koefisien fungsidiskriminankanonik maka dapat dibentuk fungsidiskriminan yaitu:

$\mathrm{D}=-3,980+0,369 X_{5}$

Tabel 5. Canonical Discriminant Function Coefficients

\begin{tabular}{|l|r|}
\hline \multirow{2}{*}{} & \multicolumn{2}{|c|}{ Function } \\
\cline { 2 - 3 } & \multicolumn{1}{|c|}{1} \\
\hline X5 & \\
(Constant) & \\
\hline
\end{tabular}

Unstandardized coefficients

\section{Menghitung Peluang Utama Kelompok}

Pada tabel 6 nilai ke 56 siswa menghasilakn masing-masing 16,37,dan 3 siswa mendapa kelompok yang sangat baik, kemudian 37 siswa menadaptkan kelompok yang baik, lalu 3 siswa di kelompokan dengan kurang baik. 
Jurnal Lebesgue : Jurnal Ilmiah Pendidikan Matematika, Matematika dan Statistika

Volume 2, No. 3, Desember 2021 hal.256-266

DOI Artikel : 10.46306/lb.v2i3.84

Tabel 6. Prior Probabilities for Groups

\begin{tabular}{lccc}
\hline \multirow{2}{*}{ HASIL RAPORT } & Prior & \multicolumn{2}{c}{ Cases Used in Analysis } \\
\cline { 3 - 4 } & & Unweighted & Weighted \\
\hline Sangat Baik & 0,333 & 16 & 16 \\
\hline Baik & 0,333 & 37 & 37 \\
\hline Kurang Baik & 0,333 & 3 & 36 \\
\hline Total & 1 & 56 & 56 \\
\hline
\end{tabular}

\section{Pembahasan}

Variabel Motivasi Belajar $\left(\mathrm{V}_{1}\right)$ menunjukan hasil nilai function 0,563 yang jauh dari nilai 1,000 yang tidak mempunyai hubungan dengan fungsi diskriminan dan di tandai dengan huruf adi varibel Motivasi Belajar . Selanjutnya Variabel II Cara Belajar $\left(V_{2}\right)$ menunjukan hasil nilai function 0,542 yang jauh dari nilai 1,000 yang tidak mempunyai hubungan dengan fungsi diskriminan dan di tandai dengan huruf a di varibel Cara Belajar. Kemudian Variabel III Kompetensi Guru $\left(\mathrm{V}_{3}\right)$ Pada tabel menunjukan hasil nilai function 0,624 yang jauh dari nilai 1,000 yang tidak mempunyai hubungan dengan fungsi diskriminan dan di tandai dengan huruf a di varibel Kompetensi Guru.

Variabel VI Lingkungan Masyarakat $\left(\mathrm{V}_{4}\right)$ menunjukan hasil nilai function 0,547 yang jauh dari nilai 1,000 yang tidak mempunyai hubungan dengan fungsi diskriminan dan di tandai dengan huruf a di variabel Lingkungan Masyarakat. Selanjutnya variabel V Sarana Prasarana $\left(\mathrm{V}_{5}\right)$ Pada tabel 4.12.menunjukan hasil nilai function 1,000 yang sama dari nilai 1,000 yang erat mempunyai hubungan dengan fungsi diskriminan dan di tandai dengan huruf a di varibel Sarana Prasarana $\left(\mathrm{V}_{5}\right)$. Dan variabel VI Lingkungan Masyarakat ( $\left.\mathrm{V}_{6}\right)$ Pada tabel 4.12.menunjukan hasil nilai function 0,547 yang jauh dari nilai 1,000 yang tidak mempunyai hubungan dengan fungsi diskriminan dan di tandai dengan huruf a di varibel Lingkungan Masyarakat $\left(\mathrm{V}_{6}\right)$

Selanjutnya rumusan masalah ke dua ( 2 ) yaitu untuk mengetahui hasil analisis diskriminan dari jawaban responden. Dari jawaban responden dapat terlihat dari banyak siswa . siswa memberikan jawaban yang bernilai skror 4 dan 5 lebih banyak di pertanyaan variabel Variabel V Sarana Prasarana $\left(\mathrm{V}_{5}\right)$ yaitu terlihat dari terbesar. Hanya variabel X5 yang memenuhi ketentuanyang bisa dimasukkan ke persamaan diskriminan. 


\section{KESIMPULAN}

Faktor paling dominan yang memiliki peran penting dalam nilai raport siswa kelas IV, Va, Vb, dan VI di MI Nurul Iman Kota Tangerang Selatan adalah varaibel lima $\left(\mathrm{V}_{5}\right)$ sarana dan prasarana di sekolah yang mempunyai nilai signifikan yaitu 0,01 , tinggi ataurendahnya nilai hasil proses pemebelajaran siswa dipengaruhi oleh sarana dan prasarana di sekolah. Fungsi Diskriminan yang diperoleh adalah $\mathrm{D}=-3,980+0,369 X_{5}$

Hasil dari ketepatan klasifikasi Model (fungsi) diskriminan yang diperoleh dengan nilai angka persentase nya adalah $60,9 \%$. Maka dari penulias meliat peresentase tersebut di atas 50\%, fungsi diskriminan tersebut untuk memprediksi faktor yang mempengaruhi hasil proses pembelajaran siswa kelas IV, Va, Vb, dan VI di MI Nurul Iman Kota Tangerang Selatan

Sebaiknya pihak sekolah MI Nurul Iman Kota Tangerang Selatan maupun orangtua siswa lebih memperhatikan faktor yang mempengaruhiproses pembelajaran siswa. Di mana sarana dan prasarana di sekolah Dimana di sekolah ialah tempat siswa mengembangkan kreatifitas nya sistem saraf motorik dan sensorik nya agar dapat berkembang dan dapat di kembangkan oleh siswa itu sendiri dengan fasilitas yang memungkinkan, komptensi guru dalam mengajar dan peran penting orang tua dalam mendidik anak nya saat sedang di rumah. Sehingga siswa dapat memberikan hasil yang memuasakan untuk sekolah dan orang tua.

\section{DAFTAR PUSTAKA}

Annas, S., (2015). Penerapan Analisis Diskriminan Dalam Pengelompokan Desa Miskin di Kabupaten Wajo. Scientific pinisi, 34-43.

Ahmadi, Abu dan Widodo Supriyono. 2013. Psikologi Belajar. Jakarta: PT. Rineka Cipta. Djaali. 2014. Psikologi Pendidikan.Jakarta: Bumi Aksara.

Ghozali, Imam.2013. Aplikasi Analisis Multivariat Dengan Program IBM SPSS 21. Semarang: Badan Penerbit Universitas Dipenogoro

Moedjiono.2012. Belajar dan Pembelajaran.Jakarta: Rineka Cipta Muhibbin Syah.2010. Psikolog Belajar Mengajar, Jakarta: Logos dan Wacana Ilmu. Sanjaya, Wina. 2010. Faktor-faktor yang Mempengaruhi Hasil Belajar. Jakarta: Prenada. Santoso, Singgih. 2015. Statistik Multivariat. Jakarta: PT Elex Media Komputtindo. Slameto, 2010. Belajar dan Faktor-Faktor yang Mempengaruhi. Jakarta: PT. Rineka Cipta. Sugiyono. 2015. Statistika Untuk Penelitian. Bandung: ALFABETA.

Hasbi, M, Suhartati Suhartati, Suryawati Suryawati, and Mukhlis Hidayat. 2018. "Analisis Diskriminan Untuk Mencari Tinggi Rendahnya Rata-Rata Hasil Belajar Mahasiswa Matematika Berdasarkan Tempat Tinggal.” Jurnal Geuthèë: Penelitian Multidisiplin 1(1): 39_ 46.(http://journal.geutheeinstitute.com/index.php/JG/article/view/7/4) 13/04/21 - 07:30

Mercurius Broto Legowo. 2016. Analisis Faktor-Faktor Yang Mempengaruhi Prestasi Akademik Mahasiswa Dengan Menggunakan Metode Analisis Diskriminan. Jurnal Teknologi, 9(2), 108-115.(https://ejournal.akprind.ac.id/index.php/jurtek/article/view/1148 ) 13/06/21 -08:00 